\title{
Integridade e ética na pesquisa e na publicação científica
}

Miriam Ventura 1

Suelen Carlos de Oliveira 2,3

doi: 10.1590/0102-311X00283521

A integridade constitui uma recente dimensão da ética em pesquisa que orienta as boas práticas científicas e demarca deveres profissionais relacionados a essa atividade. Norteadas por valores fundamentais da ciência e da ética em pesquisa, tais como a honestidade, transparência, respeito, imparcialidade, responsabilização e boa gestão da atividade científica, as discussões têm trazido e orientado importantes questões para o campo científico e ético.

A produção científica envolve a atuação de diferentes atores e uma série de atos e compromissos baseados na confiança mútua e compartilhamento de responsabilidades, que vão desde o planejamento da produção do conhecimento até a divulgação e o uso dos resultados pela sociedade.

No que se refere à divulgação, há uma relação intrínseca e indissociável entre integridade na pesquisa e a ética em publicação científica. O processo editorial é um "lócus sentinela" na identificação, na prevenção e repressão de más condutas, e elemento-chave para o bom funcionamento do sistema de pesquisa na difusão de conhecimento científico de qualidade e confiável 1.

Disputas de autoria e coautoria, conflitos de interesses, plágio e publicações duplicadas, pesquisa sem consentimento livre e esclarecido, fabricação e falsificação de dados, uso indevido de informações de banco de dados são alguns exemplos de más condutas 1,2. É impossível ter uma publicação idônea se houver má conduta na sua realização ${ }^{1}$. Nesse sentido, o processo editorial demanda políticas e boas práticas em prol da integridade na divulgação científica, possibilitando a apreciação ética das publicações, além da científica, e a prevenção de más condutas.

A atividade científica é sempre dinâmica e ampla, reflete culturas e dinâmicas sociais globais e locais. As normas éticas em pesquisa podem variar nos países e entre campos de conhecimento específicos com relação às exigências para a condução dos estudos, à necessidade de prévia avaliação ética para sua prática e à forma como é institucionalizada a revisão ética. Considerando esta diversidade das práticas científicas e institucionais e o pluralismo ético, a comunidade internacional tem chegado a consensos em relação a parâmetros e diretrizes éticas que devem ser universalmente respeitados. Este contexto plural e
1 Instituto de Estudos em Saúde Coletiva, Universidade Federal do Rio de Janeiro, Rio de Janeiro, Brasil. 2 Escola Nacional de Saúde Pública Sergio Arouca, Fundação Oswaldo Cruz, Rio de Janeiro, Brasil.

3 Universidade do Grande Rio, Duque de Caxias, Brasil. 
dinâmico traz maior complexidade e amplia as responsabilidades de pesquisadores e editores na gestão editorial científica.

Quão ativo deve ser o papel das revistas e editores na supervisão ética no processo editorial? Quais os limites e as possibilidades de se apreciar aspectos relativos à ética em pesquisa e à integridade nesse processo? Essas são indagações que têm exigido uma reflexão densa sobre a ética em publicações científicas.

Neste editorial, apresentaremos alguns aspectos críticos da supervisão ética no processo de editoração com base nas diretrizes éticas nacional e internacional e deliberações do Comitê de Ética na Publicação (COPE) 3. Tais diretrizes têm auxiliado as equipes editoriais na adoção de medidas e na tomada de decisão sobre as publicações submetidas à apreciação.

O COPE recomenda que a supervisão ética deve incluir, mas não se limitar a políticas de consentimento à publicação, cuidados em relação à conduta ética de pesquisa com seres humanos e populações vulneráveis, manuseio de dados confidenciais e práticas éticas de negócios/marketing. Destaca quatro critérios, além dos usualmente utilizados durante a revisão editorial no âmbito da supervisão: (1) validade científica-metodológica e a contribuição do estudo para o campo de conhecimento e a sociedade; (2) ponderação de riscos e benefícios da investigação para população participante; (3) procedimentos adotados de mitigação/minimização de riscos e danos individuais e coletivos; (4) comprovação e análise do cumprimento de exigências regulamentares, institucionais e/ou legais, relacionadas à avaliação ética do estudo.

As dúvidas recorrentes sobre a supervisão ética editorial na última década levada ao fórum do COPE relacionam-se à necessidade de aprovação em comitês de ética ou conselhos de revisão institucionais, anterior ou posterior ao estudo realizado, e os encaminhamentos relativos às diferentes normas dos estatutos éticos entre os países e campos do conhecimento pelos periódicos. Outro assunto recorrente é a utilização de termos de consentimento e assentimento e as possibilidades de dispensa em estudos com crianças e outros grupos vulneráveis, em estudos considerados de baixo risco, autoexperimentação e pesquisas em mídias sociais.

A política editorial de revisão por pares especialistas é medida adotada largamente pelas revistas e indispensável na análise da validade científica metodológica e contribuição do estudo para o campo de conhecimento e a sociedade. Os especialistas pareceristas verificam possíveis vieses e cofatores não considerados que podem comprometer os resultados e a admissibilidade dos procedimentos adotados no estudo pela comunidade científica. Com base na produção bibliográfica do campo, os revisores adensam sua avaliação e recomendam atualizações e esclarecimentos sobre esses e outros aspectos relacionados ao escopo da revista.

As informações metodológicas e éticas sobre o estudo realizado permitem também apreciar os critérios de ponderação de riscos e benefícios da investigação e os procedimentos adotados para a minimização de riscos e danos para a população investigada ou coletivos. A não clareza dos procedimentos adotados justifica que editores requeiram informações adicionais para seguir o processo editorial.

A exigência de avaliação e aprovação institucional prévia de estudos de pesquisas com e em seres humanos por comitês de ética, com composição multiprofissional, já estava presente na Declaração de Helsinque da Associação Médica Mundial, em 1964, e o procedimento está difundido e institucionalizado na maioria dos países. Na dúvida sobre a existência de regulamento ético e normas específicas, como a obrigatoriedade de análise ética por 
instâncias institucionalizadas nos locais em que foram conduzidas as pesquisas, a equipe editorial deve requerer esclarecimento dos pesquisadores e promover avaliação cuidadosa do seu cumprimento. O processo editorial pode até mesmo não acatar avaliação ética prévia de comitês ou vetar a publicação caso considere inapropriada a avalição realizada ou a ausência desta, diante da constatação de grave violação de deveres éticos estabelecidos no contexto local e/ou internacional.

Na proteção da vida privada e dignidade das pessoas envolvidas nos estudos são exigidas a declaração e a explicitação do processo de consentimento livre e esclarecido dos participantes das pesquisas. Alguns temas são ainda objeto de dúvidas e envolvem aspectos éticos específicos: o uso e compartilhamento de bancos de dados e os cuidados relativos à privacidade das informações, autorização de uso e segurança, com regulamentação nacional e internacional específicas 4; aplicação de métodos e técnicas comumente utilizados pelas ciências sociais e humanas na pesquisa no campo saúde 5 , como estudos etnográficos, observações participantes, interação com pessoas on-line para fins de pesquisa. Há consenso ético que todas essas modalidades devem ser consideradas intervenções dependentes de aprovação ética prévia por comitês do projeto de pesquisa e devem obter consentimento dos participantes, com possibilidades de dispensa autorizada pelos comitês e devidamente fundamentadas, justificadas, com explicitação dos cuidados adicionais e a conduta a ser adotada a posteriori 6 . Tais deveres éticos estão previstos e consensuados internacionalmente desde 1947, no Código de Nuremberg, e reiterados e atualizados nos diferentes contextos sociopolíticos, campos de conhecimento e normas éticas ao longo de décadas.

O ideal seria evitar a realização de pesquisas eticamente inadequadas, mas nem sempre é possível identificá-las na avaliação dos projetos pelos comitês de ética em pesquisa e no próprio processo de supervisão ética editorial. A postura ativa, consciente e responsável da rede de atores na identificação das más práticas é primordial na superação dessas limitações, estimulando-se o encaminhamento de objeções e comprovações aos editores das más condutas observadas pelos leitores nos estudos publicados. Os editores têm adotado medidas como a correção e retratação de artigos de acordo com a gravidade da conduta verificada após a publicação, alertando toda a comunidade acadêmica e sociedade sobre a ocorrência.

Medidas como a não aceitação de avaliações éticas anteriores ou a ausência destas quando não exigida no local do estudo ou no campo específico de conhecimento - e a retratação e correção de artigos publicados são sempre excepcionais. Exige-se, portanto, avaliação cuidadosa da equipe editorial em diálogo com as/os autoras/es, suas instituições e outras partes quando cabível, zelando pelo direito ao contraditório e ampla defesa, e deliberações devidamente fundamentadas e orientadas pelos valores que envolvem à integridade da pesquisa.

À vista dos variados interesses que permeiam as relações e atividades de pesquisa e podem influenciar sua condução e o próprio processo editorial, a identificação e tratamento de possíveis conflitos de interesses no processo editorial. Os conflitos podem ser de natureza financeira, pessoal, acadêmica, relacionada à afiliação institucional, política ou mesmo religião. Podem, ainda, ser relacionados à tecnologia utilizada na pesquisa ou na apresentação, assim como à tecnologia concorrente a essa. Há consenso sobre a importância de identificá-los e da impossibilidade de eliminá-los completamente das publicações científicas 4.

Nesse sentido, o COPE aconselha que os periódicos devem estabelecer políticas institucionais claras e objetivas que permitam a identificação e o tratamento adequado dos 
conflitos de interesses. A declaração da fonte de financiamento do estudo, dos possíveis conflitos de interesses existentes e mesmo a natureza do vínculo entre pesquisadores e financiadores são algumas das exigências requeridas pelos editores. É recomendado também que os editores incluam orientações sobre o processo de tratamento desses conflitos identificados pelos autores, revisores e editores ou entre eles. Informar sobre o potencial conflito de interesse de qualquer natureza no processo editorial e de divulgação possibilita maior transparência e credibilidade na produção científica 3,7 .

As boas práticas editoriais recomendam o fortalecimento das normas éticas consolidadas internacionalmente e a supervisão ética cuidadosa na apreciação dos estudos para a publicação. Os editores têm legitimidade reconhecida pela comunidade científica no sentido de exigir o cumprimento das normas consensuadas internacionalmente.

É certo que os processos de supervisão ética sempre serão limitados e para atingir este valor ético da integridade cada ator deve desempenhar seu papel de forma ativa, consciente e responsável. As instituições devem estabelecer políticas para promover a integridade acadêmica, investigar e resolver casos de má conduta. O pesquisador deve aderir às boas práticas e ser responsável na realização e gestão da pesquisa e divulgação dos resultados. O periódico científico deve encorajar a integridade na pesquisa e zelar pela qualidade e idoneidade da informação. O público deve exercer cidadania participativa e usar de forma consciente e crítica os resultados de pesquisa e os canais disponíveis de denúncia das más práticas.

É essencial a percepção do valor transformador do conhecimento gerado pela pesquisa, como um direito humano e fundamental ao bem-estar e ao progresso científico. Igualmente urgente a tomada de consciência ética sobre as ações de cada um nós na produção e disseminação do conhecimento científico. 


\section{Colaboradores}

Ambas as autoras contribuíram com a concepção, elaboração, redação, revisão e aprovação do manuscrito.

\section{Informações adicionais}

ORCID: Miriam Ventura (0000-0001-8520-8844); Suelen Carlos de Oliveira (0000-0002-0090-2341).
1. Coeli CM, Lima LD, Carvalho MS. Hipercompetitividade e integridade em pesquisa. Cad Saúde Pública 2017; 34:e00000718.

2. Shinkai RSA. Ética em publicações científicas. Dados eletrônicos. Porto Alegre: EDIPUCRS; 2018.

3. Committee on Publication Ethics. Guidance for editors: research, audit and service evaluations. https://publicationethics.org/files/guid ance_for_editors_research_audit_and_ser vice_evaluations_v2_0.pdf (acessado em 25/ Nov/2021).

4. Ventura M, Coeli CM. Para além da privacidade: direito à informação na saúde, proteção de dados pessoais e governança. Cad Saúde Pública 2018 ; 34:e00106818.

5. Oliveira LRC. A antropologia e seus compromissos ou responsabilidades éticas. In: Fleischer S, Schuch P, organizadoras. Ética e regulamentação na pesquisa antropológica. Brasília: Letras Livres/Editora Universidade de Brasília; 2010. p. 25-38.

6. Conselho Nacional de Saúde. Resolução no 510 , de 7 de abril de 2016. Dispõe sobre as diretrizes e normas regulamentadoras de pesquisa em ciências humanas e sociais. Diário Oficial da União 2016; 24 mai.

7. Rêgo S, Palácios M. Conflitos de interesse e a produção científica. Rev Bras Educ Méd 2008; $32: 281-2$. 